\title{
Determining the Structure of Biomaterials Interfaces using Synchrotron-based $\mathrm{X}$-ray Diffraction
}

\author{
M. McBride
}

January 24, 2002

U.S. Department of Energy

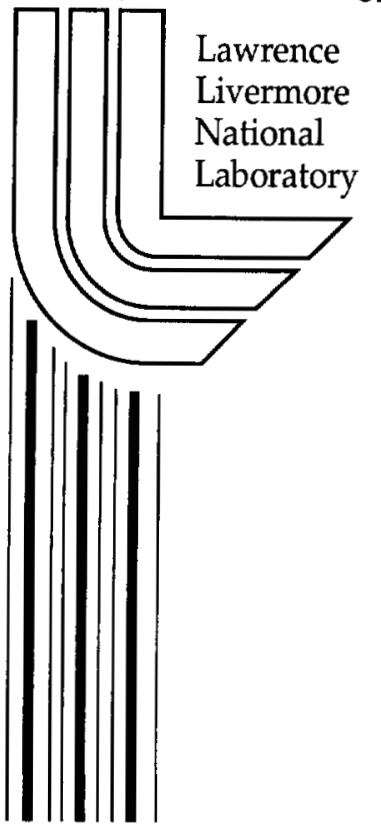




\section{DISCLAIMER}

This document was prepared as an account of work sponsored by an agency of the United States Government. Neither the United States Government nor the University of California nor any of their employees, makes any warranty, express or implied, or assumes any legal liability or responsibility for the accuracy, completeness, or usefulness of any information, apparatus, product, or process disclosed, or represents that its use would not infringe privately owned rights. Reference herein to any specific commercial product, process, or service by trade name, trademark, manufacturer, or otherwise, does not necessarily constitute or imply its endorsement, recommendation, or favoring by the United States Government or the University of California. The views and opinions of authors expressed herein do not necessarily state or reflect those of the United States Government or the University of California, and shall not be used for advertising or product endorsement purposes.

This work was performed under the auspices of the U. S. Department of Energy by the University of California, Lawrence Livermore National Laboratory under Contract No. W-7405-Eng-48.

This report has been reproduced directly from the best available copy.

Available electronically at http://www.doc.gov/bridge

Available for a processing fee to U.S. Department of Energy

And its contractors in paper from

U.S. Department of Energy

Office of Scientific and Technical Information

P.O. Box 62

Oak Ridge, TN 37831-0062

Telephone: (865) 576-8401

Facsimile: (865) 576-5728

E-mail: reports@adonis.osti.gov

Available for the sale to the public from

U.S. Department of Commerce

National Technical Information Service

5285 Port Royal Road

Springfield, VA 22161

Telephone: (800) 553-6847

Facsimile: (703) 605-6900

E-mail: orders@ntis.fedworld.gov

Online ordering: http://www.ntis.gov/ordering.htm

OR

Lawrence Livermore National Laboratory

Technical Information Department's Digital Library

http://www.llnl.gov/tid/Library.html 
This document contains no classified nor SUl: -

Reviewed by:

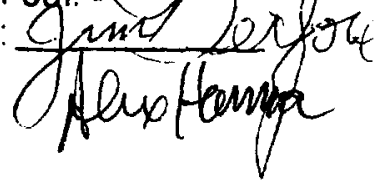

Determining the Structure of Biomaterials Interfaces using Synchrotron-based X-ray Diffraction

FY01 LDRD Final Report

Principal Investigator:

Responsible Institute Director:

Institute:

Tracking Code Number
Mary McBride

Mike McElfresh

Materials Research Institute

99-ERI-011 


\section{Background and Purpose}

Life began in a sea of electrolytes. Despite having evolved out of the oceans and on to the land, we carry the remnants of that sea within us. While fully adapted to life out of the ocean, within our skin are aqueous electrolyte solutions that mediate processes as fundamental to life as eating and breathing. The process of constructing mineralized tissues such as teeth and bones relies on these solutions to provide both the inorganic constituents of the tissue as well as organic components that serve as control agents, modifying the structure, orientation and morphology of the growing biominerals. When foreign materials such as implants and catheters are introduced into the body, the interaction between the living organism and the object is also mediated by these solutions. In both cases, the center of biochemical activity is at the interface between the solution and the solid (a region spanning a only a few monolayers, on the order of $10 \AA$ ). Consequently, any scientifically-founded ability to control either the production of natural biomaterials or the reaction of the body to synthetic biomaterials must begin with an understanding of the physics and chemistry of deposition and dissolution at liquid-solid interfaces in biological systems.

Recent advances in our ability to monitor surface evolution during solution crystallization and dissolution using scanned probe microscopy (SPM) have led to consequent advances in our understanding of the physics of these processes. ${ }^{1}$ Scanned probe microscopy (SPM) has been used to study crystallization of calcium phosphate, the mineral phase in our bones and to investigate the effect of acidic amino acids on the energetic and kinetic parameters that control the crystallization of calcium carbonate, a common biomineral. ${ }^{2}$ However, SPM studies only provide information about the morphology and growth rate of the surface; they give no information about either the atomic structure of the surface or the structure of the nearby liquid layer. 
Crystallization and dissolution from solution is a complex process involving multiple species and pathways to surface states, dehydration reactions at or near the surface and mass transport through a solvent layer which is likely to be strongly affected by the electrostatic potential of the crystal surface. Theoretical methods exist which could probe these processes through quantum electrochemical calculations of ion-ion and ion-surface interactions following some development. ${ }^{3}$ In addition, recent development of chemical force microscopy may allows us to measure the relative strength of ion/surface interactions." Until recently, we have lacked an experimental tool for probing surface and near-surface atomic structure.

Over the past few years, a handful of research groups around the world have developed the ability to look at the structure of surfaces in solutions using synchrotron radiation in a grazing angle $X$-ray scattering configuration (Figure 1a). X-ray scattering is ideal for probing interface structure because $X$ rays penetrate macroscopic quantities of fluids (such as water) with limited attenuation. The measured reflectivity of the solid-solution interface is the result of interference between $\mathrm{X}$-rays scattered from the bulk crystal, the solidsolution interfacial region, and the water layer above the surface. While the bulk structures are known a priori, the surface structure is not. The surface structure involves relatively few atoms (as compared with the bulk structures), so the greatest influence of the interfacial structure on the $\mathrm{X}$-ray reflectivity is where the bulk contributions are minimal. It is, therefore, the modulation of the $X$-ray reflectivity between the bulk Bragg peaks that provides information on the interfacial structure (Figure 1).

In-situ surface X-ray diffraction (SXRD) techniques have been used to determine the surface atomic structure of inorganic crystals, the near surface structure of liquids, the positional ordering effect of liquid layers at the interface (liquid layers may exhibit pre-ordering towards the crystalline state), the atomic structure of adsorbed layers, and the nature (geometry, stereochemistry) of adsorbate binding. ${ }^{5-8}$ SXRD provides a crucial link 
between experimental surface techniques such as SPM, and theoretical tools like kinetic Monte Carlo and molecular dynamics.

The purpose of this project is to explore the feasibility of using SXRD to determine the structure of biomineral surfaces in electrolyte solutions and of the adsorbed layer of acidic amino acids that are believed to play a central role in the control of biomineral formation and function. The work is a critical component in the development of an integrated picture of the physical and chemical basis for deposition and dissolution at solid-liquid interfaces in biological systems, and brings a new and very powerful surface-sensitive capability to LLNL. We have chosen as our model systems calcium carbonate and calcium phosphate in aspartic and glutamic acid-bearing solutions. The calcium compounds are ubiquitous among biomineral structures, both those that are beneficial such as bones and teeth, and those that are pathological such as kidney stones, while the two acidic amino acids - both as simple and poly-amino acids - are the dominant constituents of protein mixtures implicated in the control of biomineralization. The goals of the work are: 1) to determine the surface structure of pure calcium phosphate and calcium carbonate surfaces in aqueous solution using SXRD; 2) to determine how those surfaces are modified by the presence of aspartic and glutamic acid, both as the simple amino acids and as poly-aspartate and poly-glutamate and 3) to model the interactions of acidic amino acids with calcite.

\section{Proposed Activities and Technical Outcome}

FY99 Proposed Activities: This project was born of the fertile SPM studies of KDP conducted by Land and DeYoreo and an early collaboration with Elias Vlieg using SXRD to determine the structure of $\mathrm{KH}_{2} \mathrm{PO}_{4}\{100\}$ and $\{101\}$ surfaces in solution. ${ }^{6}$ The SXRD results, presented in Figure 2, show that the $[100\}$ face is a simple truncation of the bulk with very little surface relaxation, but that the $\{101\}$ face is comprised of a slightly relaxed potassium layer, giving the surface an overall net positive charge. Figure 2 shows the measured crystal truncation rods for the $\{101\}$ surface, and those expected for a 
K-terminated surface, as well as the inferred structure of the crystal perpendicular to the $\{101\}$ surface. These results provide the first feasible explanation for why cationic impurities such as $\mathrm{Fe}^{3+}$ and $\mathrm{Al}^{3+}$ are strongly segregated into the $\{100\}$ sectors of KDP and strongly rejected from the $\{101\}$ sectors. The repulsive nature of the cation-\{101\} surface interaction should prevent the impurities from adsorbing onto the surface while the neutral nature of the cation- $\{100\}$ surface interaction should allow these impurities to readily adsorb. Comparison of our SPM results ${ }^{9}$ with SXRD measurements ${ }^{6}$ on the $\{100\}$ surface following introduction of $\mathrm{Fe}^{3+}$ show that the impurities do indeed readily adsorb on to the face but do not form an ordered layer.'

The FY99 proposal had three components: 1) design and construction of a flow cell similar to what we assembled for our work on $\mathrm{KH}_{2} \mathrm{PO}_{4}$, 2) the determination of the surface structure of pure calcium phosphate and calcium carbonate surfaces in aqueous solution, and 3) determination of how those surfaces are modified by the presence of aspartic and glutamic acid both as the simple amino acids and as poly-aspartate and poly-glutamate.

FY99 Technical Outcome: Collaborations were formed with both the U.S. (Sturchio, Fenter, et. al ) and European (Vlieg) groups working in this area. Because of these collaborations there was no need to construct our own sample cells. Fenter and Sturchio reported the structure of calcite (104) faces in water ${ }^{7,10}$ before this work was initiated, so we used their expertise as the starting point in our work to determine how (104) calcite surfaces are modified in the presence of aspartic or glutamic acid. The first data on the calcite-aspartic acid system was taken at the Advanced Photon Source (APS) at Argonne National Laboratory. The measurements, presented in Figure 3, show clear evidence for the presence of an organic thin film on the $\{104\}$ face. Due to beam-induced damage of the film, which led to significant intensity variations, we were not able to draw conclusions about the ordering of the film. We grew calcite crystals in D- (right handed) and L- (left handed) aspartic acid (Figure 4) and analyzed the crystals in the context of our AFM 
results. ${ }^{2}$ We found that the crystals became elongated in the (001) directions and expressed what appeared to be an unequal mixture of (110) and (1-10) facets, with the symmetry of the new faces displaying lefthanded/righthanded symmetry depending on whether the aspartic acid is $\mathrm{D}$ or $\mathrm{L}$. The combination of these results indicate that: 1) aspartic acid adsorbs to the crystal surface, 2) there is stereochemical control over the resulting film, 3) future SXRD should be applied to the (110) and (1-10) faces, not the (104) face expressed in the aspartic acid free system.

FY00 Proposed Activities: Building upon the results of FY99, in FY00 we proposed to use SXRD to determine the surface structures of the (110) and (1-10) calcite faces (referred to hereafter as $\{h k 0\})$. In parallel with our SXRD work, we proposed to use the commercial software package (Cerius2) to model the interactions of aspartic and glutamic acids with $\{\mathrm{hk} 0\}$ calcite surfaces. We proposed to study the asparatic acid-modified surfaces using FTIR to look for differences between aspartic and glutamic acid adsorption to (104), (110) and (1-10) faces of calcite. And finally, we proposed to study the adsorption of both polyaspartic and polyglutamic acids on calcite.

FY00 Technical Outcome: To perform SXRD studies on [hk0\} faces of calcite, we first had to grow high quality crystals of suitable size. Despite our efforts, crystals suitable for SXRD work were not obtained. Using a variety of experimental techniques that are independent of crystal size or quality, including XPS, NEXAFS, FTIR, Raman, SEM, and AFM, we determined that aspartic acid strongly modifies calcite surfaces but is not incorporated into bulk and does not bind the (104) faces of calcite; that the stereospecific binding interaction involves two sites on (hk0\} faces, while interactions on [104\} faces are insignificant; and that surface modifications are due to a thermodynamically driven process, not a kinetic one. ${ }^{11}$ We employed a commercial software package (Cerius2) to model the interactions of aspartic and glutamic acids with $\{\mathrm{hk}$ 어 calcite surfaces. Our efforts to model the 
interactions of both D-and L-aspartic acid with $\{\mathrm{hk} 0\}$ faces of calcium carbonate showed that the differences in binding geometries were quite subtle, and that sophisticated energy calculations were necessary to reveal any significant differences. We formed a collaboration with Andrezj Wierzbicki and Steven Sikes (University of Southern Alabama), taking advantage of their ability to perform such calculations. ${ }^{12}$

We proposed to study the adsorption of both poly aspartic and polyglutamic acids on calcite. However, Sikes and Wierzbicki had previously modeled the behavior of polyaspartic acid in the presence of calcite, ${ }^{13}$ and their calculations suggested that polyaspartic acid would likely not interact with calcite in an aqueous solution in a manner suitable for SXRD; predictions indicated that polyaspartic acid was likely to bind calcite using only a few residues while the rest of the biopolymer coiled and bound to itself.

A more appropriate biopolymer, and one with potentially far-greater impact on biomineralization studies was found in a number of proteins extracted from abalone. These proteins are implicated in the control of biomineralization in abalone; moreover, it has been suggested that certain proteins can induce a phase transition whereby biomineralizing calcite can be induced to phase-transition to aragonite, a polymorph of calcite. ${ }^{14,15} \mathrm{We}$ formed another collaboration with researchers at UC Santa Barbara, where molecular biologists were able to provide adequate quantities of purified proteins for use in SXRD studies. We submitted a proposal to the APS to study the calcite-to-aragonite transition, and we were awarded 6 days of Independent Investigator beamtime.

FY00 also brought the chance to participate in a study of the formation of liquid layers of tin on the atomically-smooth (111) surfaces of crystals of germanium, the opportunity to establish independent-investigator beamtime at both APS and ESRF, as well as an invitation to speak at the APS. Measurements were made on the structure of rings of liquid $\mathrm{Sn}$ on $\mathrm{Ge}(111)$ in late June, FY00; these results have been described elsewhere. ${ }^{16}$ 
FY01 Proposed Activities: Our primary goal in FY01 was to complete the calcite work. Specifically, we proposed to investigate a protein-mediated calcite-aragonite phase transformation using SXRD to confirm the presence of the two mineral species and to obtain the structure at the mineral-protein interface, the mineral-mineral interface, and the mineral-liquid interface. We proposed to complete the energy calculations for adsorbate binding to \{hk0\} calcite faces, and finally, we proposed to conduct SXRD studies on crystals of calcuim phosphate to determine the surface structure of pure calcium phosphate in aqueous solution and how the surface is modified by the presence of aspartic acid.

FY00 Technical Outcome: Having established LLNL-Independent Investigator beamtime at APS, we conducted studies of the protein-mediated calcitearagonite transition. We detected a single mineral phase - calcite; this result is at odds with work published by others. ${ }^{15,17}$

Our collaborators at USA completed the molecular modeling and energetics calculations for the interactions of both D-and L-aspartic acid with [hk0) faces of calcium carbonate. The calculated binding energies of D- and Laspartic acid binding to $\{104\}$ faces show that there is no difference in binding energy between the two enaintiomers because both adsorbates can rotate to maximize their binding energy (Figure 5). However, specific preferences in adsorbate binding and subtle differences in the energetics of adsorbate binding are observed for calculations involving $\{\mathrm{hk} 0\}$ faces. The calcite data obtained using AFM, a variety of spectroscopic techniques, the modeling, and a theoretical study have been published in a benchmark biomineralization paper. ${ }^{11}$ In the paper, we describe the nature of adsorbate binding to specific calcite crystal faces (e.g., geomtry, stereospecificity) and the emergence of chirality from an achiral crystal. The work represents a big step forward in our ability to address fundamental biomineralization questions. Moreover, these results have implications in fields like materials science, where we 
have shown how a material can be altered without changing the inherent properties of the material, and geology, where questions on the emergence of chirality relate to origins-of-life issues.

We proposed to expand our studies to calcium phosphates (e.g., brushite and fluorapatite); however suitable crystals were not obtained. We directed our efforts to the barite $\left(\mathrm{BaSO}_{4}\right)$-water interface, another important mineral for which suitable crystals were readily obtained. Barite is intensely studied because of the problem of barite scale formation in the petroleum industry. We recently reported our very high resolution $(\sim 1 \AA)$ structures of barite (001) and (210) cleavage surfaces in contact with water. ${ }^{18}$ In addition, we completed a study of barite cleavage surfaces in the presence of the growth inhibitor, HEDP (1-hydroxy-1,1-diethyl phosphonic acid); those results will be published in a forthcoming manuscript.

\section{Relevance to LLNL programatic missions}

The impact of this work on LLNL programs is three-fold. First, the lab has identified biomaterials as a critical area for the future. The Healthcare Technologies Program develops devices for use in the body that rely on biocompatibility. Developing a core competency in biomaterials R\&D will feed this developing program. The Materials Research Institute (MRI) has also identified Biomaterials as one of its thrust areas. Because this project has a strong scientific component in the area of biomaterials, involves outside collaborations with U.C. Davis, U. Nijmegen and Argonne National Lab, dovetails with existing Chemistry and Materials LDRD and BES efforts that involve U.C. Davis and Georgia Tech Investigators, and utilizes the synchrotron sources at Argonne and Grenoble, it is well suited to the MRI mission. Second, the project builds upon the initial studies of the fundamental physics and chemistry underlying crystal growth. Developing an integrated picture of the physical and chemical basis for deposition and dissolution at solid-liquid interfaces has proved critical in the growth of large, high-quality KDP and DKP crystals for the NIF. Finally, low angle X-ray 
scattering has become an important tool for investigating materials structure, both bulk and surface. Currently, LLNL lacks competency in this area. It is our hope that this project will provide the first step towards developing an expertise in this area. 


\section{References}

1 Land, T.A., De Yoreo, and J.J., Lee, J.D., "In situ AFM investigation of canavalin crystallization kinetics", Surf. Sci. 384, 136 (1997).

2 Teng, H, H., Dove, P. M., Orme, C. A., DeYoreo, J. J. "Thermodynamics of calcite growth: Baseline for understanding biomineral formation" Science, 282, 724 (1998).

3 Wilson, W. D., Schaldach, C. M., Bourcier, W. L., Chem. Phys. Lett. 267, 431 (1997).

4 Noy, A., Sanders, C.H., Vezenov, V., Wong, S.S., Leiber, C.M., "Chemically-sensitive imaging in tapping mode chemical force microscopy: relationship between phase lag and adhesion", Langmuir 14 1508 (1998).

5 Gidalevitz, D., Feidenhansl, R., Smilgies, D.M. and Leiserowitz, L., "X-ray scattering from the surface of organic crystals", Surface Review and Letters, 4, 721 (1997).

6 De Vries, S.A., Goedtkindt, P., Bennett, S.L., Huisman, W.J., et. al. "Surface structure of $\mathrm{KH}_{2} \mathrm{PO}_{4}$ crystals growing from aqueous solution", Phys. Rev Lett., 80, 2229 (1998).

7 Fenter, P. and Sturchio, N., "Structure and Growth of Stearate Monolayers on Calcite: First Results of an In-situ X-ray reflectivity Study", Geochim. et Cosmochim Acta, 63, 3145 (1999).

8 Gidalevitz, D., Feidenhansl, Matlis, S., Smilgies, P.M. et al. "Monitoring In-situ Growth and Dissolution of Molecular Crystals: Towards Determination of Growth Units", Angew. Chem. Int. Ed. Eng. 36, 955 (1997).

9 Land, T.A., Martin, T., Potapenko, Palmore, G.T.R. and De Yoreo, J.J., "Recovery of crystal surfaces from impurity poisoning", Nature, 399, 442, (1999).

10 Fenter, P., Geissbuhler, P., DiMasi, E., Srajer, G., et al. "Surface speciation of calcite observed in situ by high-resolution X-ray reflectivity" Geochim. et Cosmochim Acta, 64, 1221 (2000).

11 Orme, C. A., Noy, A., Wierzbicki, A., McBride, M.T., et al. "Formation of chiral morphologies through selective binding of amino acids to calcite surface steps" Nature, 411, 775, (2001). 
12 Madura, J. D., Baran, K., Wierzbicki, A. "Molecular recognition and binding of thermal hysteresis proteins to ice. J. Mol. Recog. 13, 101, (2000).

13 C.S. Sikes, M.L. Yeung and A.P. Wheeler; A.P. Wheeler, K.C. Low, C.S. Sikes, In Surface Reactive Peptides and Polymers: Discovery and Commercialization. C.S. Sikes and A.P. Wheeler, Eds., (ACS Books: Washington, 1990).

14 A. Berman, L. Addadi, and S. Weiner, Nature 331, 546 (1988).

15 Belcher, A.M., Wu, X.H., Christenson, R.J., Hansma, P.K.et.al. “Control of Crystal Phase Switchingand Orientation by Soluble Mollusc-Shell Proteins." Nature, 381, 56 (1996).

16 Reedijk, M. F., Arsic, J., de Theije, F. K., McBride, M. T., et al. "Structure of liquid Sn on Ge(111)" - art. no. 033403. Phys. Rev. B. 6403, 3403, (2001).

17 Thompson, J. B., Paloczi, G. T., Kindt, J. H., Michenfelder, M. et al. "Direct observation of the transition from calcite to aragonite growth as induced by abalone shell proteins" Biophys. J., 79, 3307, (2000).

18 Fenter, P., McBride, M. T., Srajer, G., Sturchio, N. C., et al. "Structure of barite (001)- and (210)-water interfaces" J. Phys. Chem B., 105, 8112, (2001). 
(a)

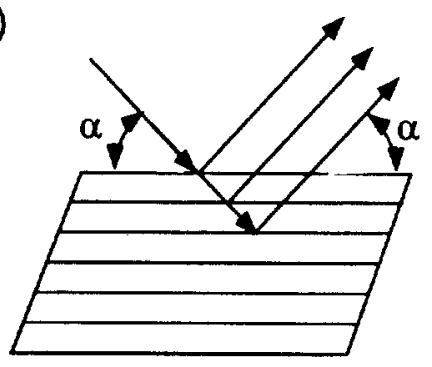

(b)

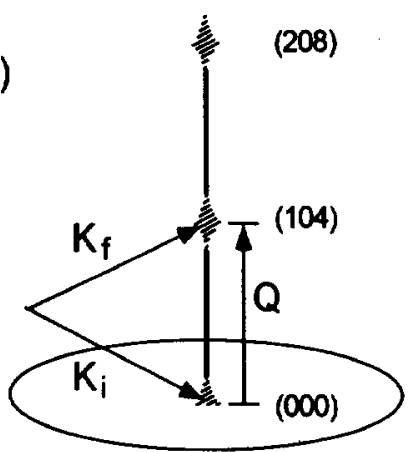

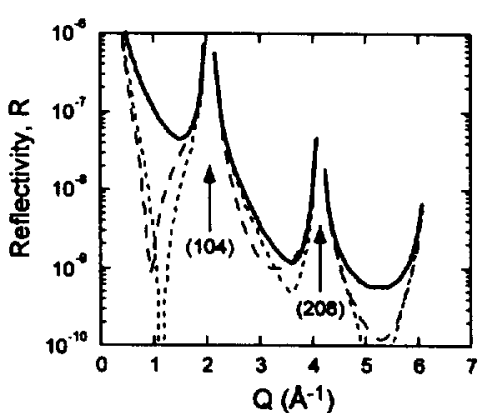

Figure 1. a) Schematic representation of the $X$-ray scattering geometry. $X$-rays are incident upon the surface at a grazing angle, $\alpha$, and specularly reflected. b) The magnitude of the specular reflection, the perpendicular momentum transfer $\mathbf{Q}$ is given as $\mathbf{Q}=\mathrm{k}_{\mathrm{f}}-\mathrm{k}_{\mathrm{i}}$. c) Diffraction at bulk Bragg peaks (e.g., (000), (104)) give the bulk structure, while intensity modulations between bulk Bragg peaks that deviate from the bulk structure give the interfacial structure. 


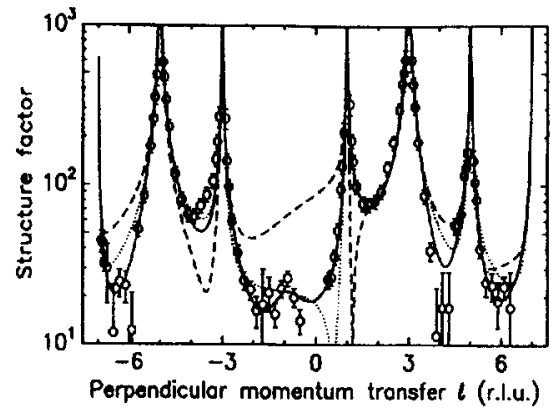

a

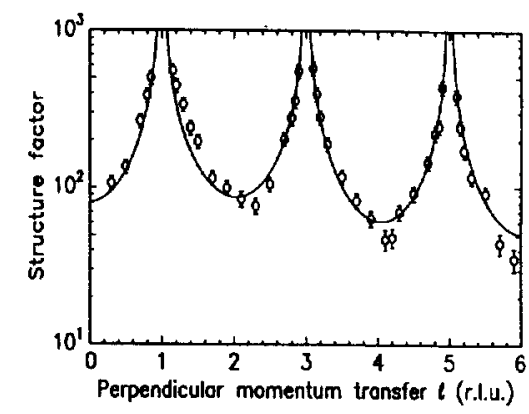

C

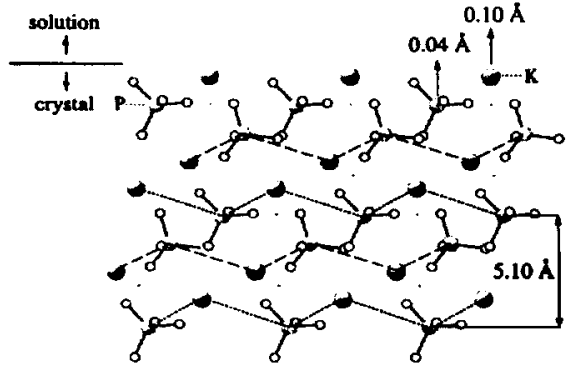

b
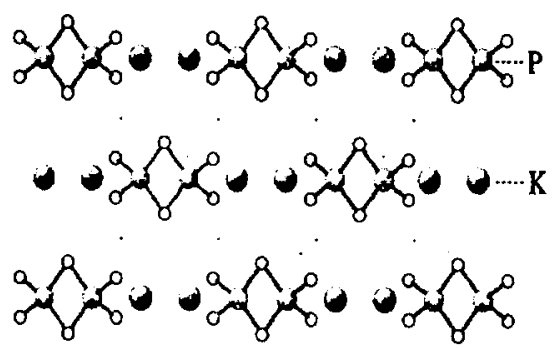

d

Figure 2. a) Structure factor amplitudes for the (hk) $=(10)$ crystal truncation rod for $\mathrm{KDP}(101)$. The dotted line is calculated for a bulk $\mathrm{K}^{+}$terminated surface, the dashed line for the $\mathrm{H}_{2} \mathrm{PO}_{4} \cdot$ terminated one. b) Schematic side view of the best fit structure models of the $\mathrm{KDP}(101)$ face. The big circles are the potassium atoms while the $\mathrm{PO}_{4}$ groups are depicted as a circle for the phosphor atom connected to the four neighboring oxygen atoms, shown as small white circles. Hydrogen atoms are shown as dots. c) Calculated and measured structure factor amplitude for $\mathrm{KDP}(100)$. d) $\mathrm{KDP}(100)$ surface expresses equal mixtures of cations and anions, resulting in a neutral surface. 


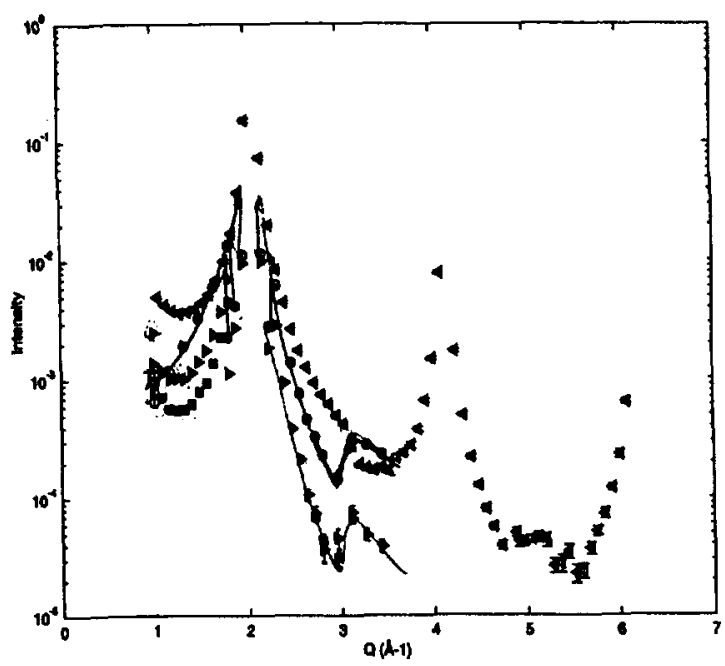

Figure 3. First measurements of the calcite (104) crystal surface in the presence of a solution containing aspartic acid. The drop in intensity from the pure calcite curve (uppermost) to those for the aspartic acid bearing solutions are a result of the formation of the organic film. The appearance of structure in the range of 2 to $4 \AA^{-1}$ range suggests ordering in the film. 

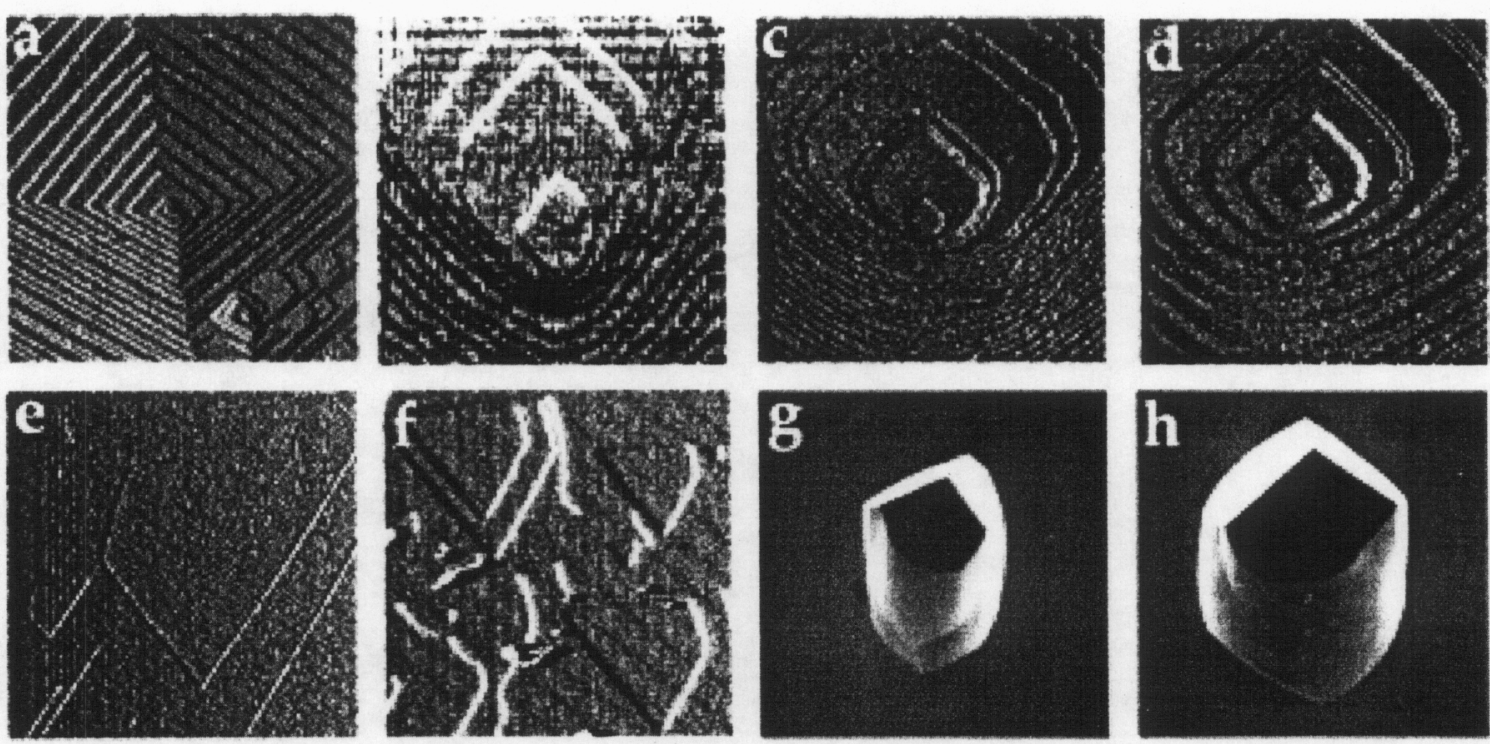

Figure 4. Images showing the effect of amino acids on calcite morphology. af: AFM images showing the effect of amino acids on the growth-hillock and dissolution pit geometry a) pure calcite growth hillock. b-d: Growth hillocks following addition of supersaturated solutions of b) $0.01 \mathrm{M}$ glycine, an achiral amino acid c) $0.01 \mathrm{M}$ L-aspartic acid, d) $0.01 \mathrm{M}$ D-aspartic acid. e,f: Corresponding dissolution pits for the two aspartic acid solutions. $g, h$ ) SEM micrographs of calcite crystals nucleated on $\mathrm{COOH}$-terminated regions of patterned self-assembled monolayers of alkane thiols and grown in the presence of $0.01 \mathrm{M} \mathrm{D}$-asparatic and L-aspartic acid. The images show that the macroscopic crystals exhibit a columnar morphology with the three \{104\} facets forming a cap at each end. The straight edges of these caps correspond to the obtuse steps that are the two steps in the upper half of the AFM images. The shape and chirality of each facet matches that of the growth hillocks shown in $\mathbf{c}$ and $\mathbf{d}$. The curved surfaces that form the barrel of each column have general $\{\mathrm{hk} 0\}$ orientations. 


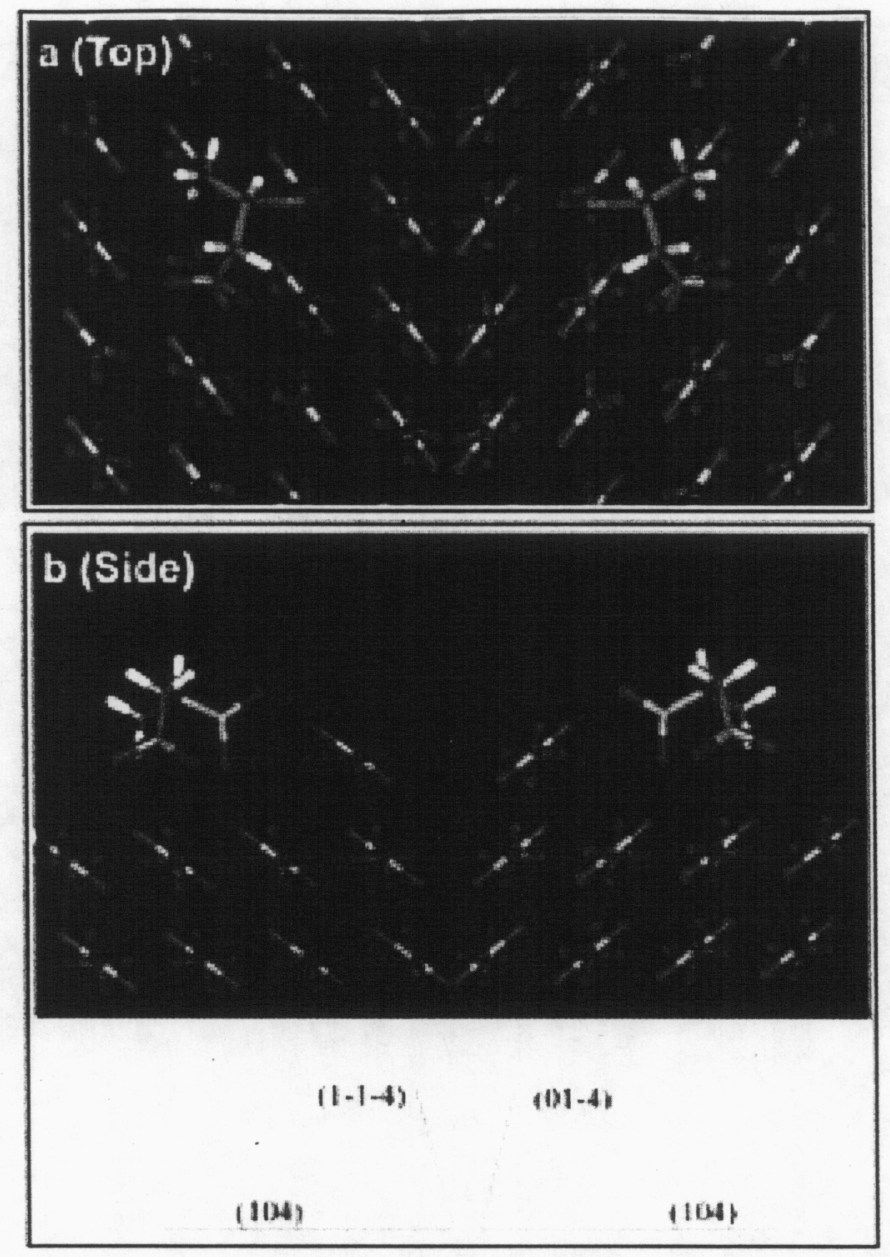

Figure 5. Geometry of binding for aspartic acid adsorbed to the single (104) steps of calcite. A) Top view and b) side view of L-aspartic (left) and Dasparatic (right) binding to the steps of calcite. 